\title{
Nominations for the Editorship of Psychonomic Bulletin \& Review
}

Nominations are solicited for the editorship of Psychonomic Bulletin \& Review. The term of the present editor, David Balota, expires at the end of 2006. The new editor will begin an official five-year term on January 1, 2007, and will begin to receive manuscripts early in January 1, 2006. The Publications Committee of the Psychonomic Society expects to appoint the new editor by November 2005.

Nominations (including self-nominations) should be submitted by May 1, 2005, to:

John T. Wixted

Chair, Psychonomic Bulletin \& Review Search Committee

Department of Psychology, 0109

University of California, San Diego

La Jolla, CA 92093-0109

jwixted@ucsd.edu 